\title{
Adsorption of aluminium ions by montmorillonite: influence on aluminium speciation
}

\author{
M. G. M. Bruggenwert, P. Keizer and P. Koorevaar \\ Department of Soil Science and Plant Nutrition, Wageningen Agricultural Univer- \\ sity, P.O. Box 8005, NL 6700 EC Wageningen, Netherlands
}

Received 16 April 1987; accepted 4 June 1987

Key words: aluminium speciation, aluminium adsorption, irreversible aluminium adsorption, hydrolysis of aluminium ions, salt effect

\begin{abstract}
A model describes the effect of sorption, charge-determined selectivity and chemical equilibria among aluminium species on the aluminium-clay interaction. The model fits the results of an experiment, involving adsorption of aluminium onto sodium montmorillonite and explains apparently contradictory experimental results about aluminium-clay interaction described in the literature.
\end{abstract}

\section{Introduction}

In order to characterize the influence of aluminium on soil, insight in the mechanisms controlling the amount and type of aluminium species present in soils is required. Interaction between clay minerals and aluminium ions influences aluminium speciation (Chernov, 1947; Haward \& Coleman, 1954; Ragland \& Coleman, 1960; Frink \& Peech, 1963; Bruggenwert, 1972; Brown \& Newman, 1973; Bloom et al., 1977; Hodges \& Zelazny, 1983). To explain phenomena related to the interaction, special attention has been paid to the influence of clay on the degree of hydrolysis of aluminium species. Ragland \& Coleman (1960) equilibrated an aluminium montmorillonite (prepared with $1 / 3 \mathrm{~mol} / \mathrm{l} \mathrm{AlCl}_{3}$ ) with a $10^{-3} \mathrm{~mol} / 1 \mathrm{AlCl}_{3}$ solution and observed adsorption of aluminium ions in excess of the cation exchange capacity (CEC) and $\mathrm{H}$ ion production equivalent to this excess. They concluded that the hydrolysis of aluminium ions is increased by clay. Obviously, the clay acted as a catalyst for the precipitation of $\mathrm{Al}(\mathrm{OH})_{3}(\mathrm{~s})$. Usually adsorbed aluminium ions are only partially exchangeable upon extraction with neutral salts (Hsu \& Rich, 1960; Nye et al., 1961; Coulter, 1969; Coleman \& Thomas, 1967). This phenomenon was attributed to increased hydrolysis of adsorbed $\mathrm{Al}^{3+}$ ions upon addition of neutral salts, or to hydrolysis of exchanged $\mathrm{Al}^{3+}$ ions followed by readsorption of the hydrolysis products. These processes could explain both the decrease of $\mathrm{pH}$ upon increasing salt level of a suspension of aluminium-clay, and the higher $\mathrm{H} / \mathrm{Al}$ ratio in an 
equilibrium solution of a clay suspension than in a 'stoichiometrically neutral' solution of aluminium salts of the same molarity in aluminium (Kaddah \& Coleman, 1967). These authors, however, observed a decreasing $\mathrm{H} / \mathrm{Al}$ ratio in the equilibrium solution with increasing ionic strength, which could not be explained. Bloom et al. (1977) indicated that the calcium-clay surface promoted hydrolysis of $\mathrm{Al}^{3+}$ at partial coverage of exchange sites by aluminium.

While many authors explained their experimental results on the basis of preferential adsorption of hydrolysis products of $\mathrm{Al}^{3+}$ ions by clays, Frink (1960) and Frink \& Peech (1963) presented a model based on adsorption of $\mathrm{Al}^{3+}, \mathrm{AlOH}^{2+}$ and $\mathrm{H}^{+}$ions according to their Boltzmann accumulation factor. Because $\mathrm{Al}^{3+}$ ions should be preferred to $\mathrm{AlOH}^{2+}$ ions, these authors concluded that addition of clay suppresses the hydrolysis of aluminium ions. At $\mathrm{pH} 5$ and at partial coverage of the montmorillonite with $\mathrm{Al}^{3+}$ ions Bruggenwert (1972) observed suppressed hydrolysis of aluminium ions in a sodium-aluminium montmorillonite suspension but increased hydrolysis of aluminium ions in a calcium-aluminium montmorillonite suspension. Hodges \& Zelazny (1983) added aluminium, with an $\mathrm{OH} / \mathrm{Al}$ ratio of $0.75-$ 2.0 , to kaolinite. They measured suppressed hydrolysis at low loading rates and increased hydrolysis of the adsorbed and fixed species at high loading rates. The latter authors propose an adsorption mechanism controlled by exchange sites with different affinities.

With respect to the $\mathrm{pH}$ value in an aluminium-clay system the following may be noted. In a stoichiometrically neutral (SN) aluminium salt solution (i.e. an aluminium salt solution without any addition of free acid or alkali) the $\mathrm{pH}$ is, in the absence of precipitation, fully determined by the concentration level of total aluminium in solution. A decrease of this concentration leads to an increase of $\mathrm{pH}$. When only $\mathrm{Al}^{3+}$ is removed by preferential adsorption on clay, the effect is thus simply an increase of $\mathrm{pH}$. However, removal of aluminium from the solution by means of precipitation produces protons and, at the simultaneous occurrence of both adsorption and precipitation, counteracts the $\mathrm{pH}$ increase caused by adsorption; this may eventually even lead to $\mathrm{aH}$ decrease during aluminium removal from the solution.

This paper presents a simple quantitative model based on adsorption in accordance with the charge of the species involved, precipitation of $\mathrm{Al}(\mathrm{OH})_{3}(\mathrm{~s})$ and chemical equilibrium between dissolved aluminium species. Removal of aluminium ions from solutions by the different processes is indicated as sorption. The model has been tested using experimental results on the influence of the aluminium/clay ratio on aluminium speciation and $\mathrm{pH}$ in a sodium-aluminium clay suspension.

The advantage of this new model as compared with classical exchange models is that the phenomena reported in the literature, concerning aluminium-clay interactions, can be explained in a coherent way. The model bridges the apparent controversy between hypotheses concerning this interaction.

\section{General considerations}

The interaction between aluminium ions and clay minerals is influenced by adsorption of $\mathrm{Al}^{3+}$ ions and their hydrolysis products on the one hand and by chemical pro- 
cesses involving aluminium ions (hydrolysis, polymerization, precipitation) on the other hand.

A key variable in describing the interaction of aluminium ions with clay minerals is the ion activity product (IAP):

$$
\operatorname{IAP}=\left(\mathrm{Al}^{3+}\right)\left(\mathrm{OH}^{-}\right)^{3}
$$

where $(\mathrm{k})$ indicates the activity of species $\mathrm{k}$.

In a $\mathrm{SN}$ aluminium salt solution IAP increases with decreasing aluminium concentration because the effect of a decrease of the total aluminium concentration on IAP is dominated by the increase of $\mathrm{pH}$. In concentrated aluminium salt solutions $(>0.1 \mathrm{~mol} / \mathrm{l})$ IAP is smaller than the solubility product of gibbsite, while at a low total aluminium concentration $\left(<10^{-3} \mathrm{~mol} / \mathrm{l}\right)$ IAP surpasses the solubility product of a fresh $\mathrm{Al}(\mathrm{OH})_{3}$ precipitate $\left(>10^{-33}\right)$. Thus the paradox arises that due to dilution of an aluminium salt solution, $\mathrm{Al}(\mathrm{OH})_{3}(\mathrm{~s})$ will eventually precipitate. The reverse of this paradox is that, in principle, it is possible to dissolve $\mathrm{Al}(\mathrm{OH})_{3}(\mathrm{~s})$ by addition of a $\mathrm{SN}$ aluminium salt. Addition of a sodium montmorillonite to a $\mathrm{SN}$ aluminium salt solution leads to a redistribution of the aluminium ions over the solution and adsorption phase, resulting in a decrease of dissolved aluminium. If in both phases the aluminium solution is stoichiometricaly neutral, then:

$$
\operatorname{IAP}_{\mathrm{a}, \mathrm{SN}}<\mathrm{IAP}_{\mathrm{c}, \mathrm{SN}}
$$

where $\mathrm{IAP}_{\mathrm{a}, \mathrm{SN}}$ is the ion activity product $\left(\mathrm{Al}^{3+}\right)\left(\mathrm{OH}^{-}\right)^{3}$ of a $\mathrm{SN}$ aluminium salt solution with the same aluminium concentration as in the adsorption phase and $\operatorname{IAP}_{\mathrm{e}, \mathrm{SN}}$ is the ion activity product for the equilibrium solution phase.

The situation described in Eq. 2 will not occur in reality. The species involved will be adsorbed in accordance with their charge, leading to:

$$
\begin{aligned}
& \left(\mathrm{Al}^{3+}\right)_{\mathrm{a}}=\left(\mathrm{Al}^{3+}\right)_{\mathrm{e}} \times B^{3} \\
& \left(\mathrm{H}^{+}\right)_{\mathrm{a}}=\left(\mathrm{H}^{+}\right)_{\mathrm{e}} \times B
\end{aligned}
$$

The subscripts a and e again indicate the adsorption phase and the equilibrium bulk solution phase, respectively. $B$ is the Boltzmann factor, $\exp (-e \psi / k T)$. As a consequence of this selective adsorption the situation at equilibrium can be described by:

$$
\operatorname{IAP}_{\mathrm{a}}=\operatorname{IAP}_{\mathrm{e}}
$$

This is so because the ion activity product in the adsorption phase equals:

$$
\operatorname{IAP}_{\mathrm{a}}=\left(\mathrm{Al}^{3+}\right)_{\mathrm{e}}(\bar{B})^{3}\left(\mathrm{OH}^{-}\right)_{\mathrm{e}}^{3}(\bar{B})^{-3}=\left(\mathrm{Al}^{3+}\right)_{\mathrm{e}}\left(\mathrm{OH}^{-}\right)_{\mathrm{e}}^{3}
$$

with $\bar{B}$ the mean value of $B$ in the adsorption phase. Thus, although the activity of 
both $\mathrm{Al}^{3+}$ and $\mathrm{OH}^{-}$near the exchanger deviates strongly from that in the bulk solution, the IAP is the same because the terms including $\bar{B}$ cancel, at least if the adsorption is exclusively defined by electrostatic effects.

The effect of the selective adsorption on the situation in both phases can be concluded from the combination of Eqs. 2 and 4:

$$
\operatorname{IAP}_{\mathrm{a}, \mathrm{SN}}<\operatorname{IAP}_{\mathrm{a}}=\mathrm{IAP}_{\mathrm{e}}<\mathrm{IAP}_{\mathrm{c} . \mathrm{SN}}
$$

Eq. 6 indicates that compared with a SN aluminium salt solution with the same aluminium concentration, the adsorption phase is proton depleted while the equilibrium bulk solution is proton enriched. The magnitude of the $\mathrm{H}$ ion depletion and $\mathrm{H}$ ion enrichment and the related value for $\operatorname{IAP}_{\mathrm{a}}$ and $\operatorname{IAP}_{\mathrm{e}}$ is determined by:

a. the selective adsorption which is a function of the symmetry of the system (total amount of cations per equivalent clay), nature of the cations $(\mathrm{Al}, \mathrm{Na}, \mathrm{Ca}, \ldots$. . and the salt concentration in the equilibrium bulk solution.

b. secondary chemical reactions among the aluminium species in the adsorption phase, as a reaction on the $\mathbf{H}$ ion depletion induced by the selective adsorption. Assuming that $\mathrm{IAP}_{\mathrm{a}}$ cannot exceed the solubility product, $K_{\mathrm{sp}}$, of (fresh) aluminium hydroxide, it leads to:

$$
\mathrm{IAP}_{\mathrm{a}} \leqslant K_{\mathrm{sp}}
$$

The total charge of sorbed aluminium decreases when part of this aluminium hydrolyses (including the formation of $\mathrm{Al}(\mathrm{OH})_{3}(\mathrm{~s})$ ). Since the $\mathrm{CEC}$ of the clay should be compensated by an equivalent sorption of cations (neglecting anion exclusion) this means that an 'extra' amount of cations will be sorbed that is equal to the amount of protons brought into the equilibrium bulk solution by the formation of $\mathrm{Al}(\mathrm{OH})_{3}(\mathrm{~s})$ and other hydrolysis products. This process continues until $\operatorname{IAP}_{\mathrm{e}}=\operatorname{IAP}_{\mathrm{a}}\left(=K_{\mathrm{sp}}\right)$.

\section{Model formulation}

The behaviour of aluminium in clay suspensions is simulated in a (selective adsorption precipitation) model involving:

a. Chemical equilibrium among $\mathrm{Al}^{3+}, \mathrm{AlOH}^{2+}, \mathrm{Al}_{2}\left(\mathrm{OH}_{2}\right)^{4+}, \mathrm{Al}_{2}\left(\mathrm{OH}_{3}\right)^{3+}$ and $\mathrm{Al}(\mathrm{OH})_{3}(\mathrm{~s})$ if present. The equilibria are defined as follows:

$$
\begin{aligned}
K_{11} & =\left(\mathrm{AlOH}^{2+}\right)\left(\mathrm{H}^{+}\right) /\left(\mathrm{Al}^{3+}\right) \\
\mathrm{p} K_{11} & =5.0(\text { Schofield \& Taylor, 1954; Kubota, 1956; Frink, 1960) } \\
K_{22} & =\left(\mathrm{Al}_{2}(\mathrm{OH})_{2}^{4+}\right)\left(\mathrm{H}^{+}\right)^{2} /\left(\mathrm{Al}^{3+}\right)^{2} \\
\mathrm{p} K_{22} & =7.55(\text { Faucherre, } 1954 ; \text { Kenttämaa, 1955) } \\
K_{23} & =\left(\mathrm{Al}_{2}(\mathrm{OH})_{3}^{3+}\right)\left(\mathrm{H}^{+}\right)^{3} /\left(\mathrm{Al}^{3+}\right)^{2} \\
\mathrm{p} K_{23} & =10.3(\text { Brosset et al., } 1954)
\end{aligned}
$$




$$
\begin{aligned}
& K_{\mathrm{sp}\left(\mathrm{Al}(\mathrm{OH})_{3}\right)}=\left(\mathrm{Al}^{3+}\right)\left(\mathrm{OH}^{-}\right)^{3} \\
& \mathrm{p} K_{\mathrm{sp}}=33.5(\text { Sillén \& Martell, 1964) }
\end{aligned}
$$

Activity coefficients, $f_{\mathrm{k}}$, are calculated with the Debye-Hückel equation:

$$
-\log f_{\mathrm{k}}=A z_{\mathrm{k}}^{2} \vee I /\left(1+\stackrel{\circ}{\mathrm{k}}_{\mathrm{k}} B \vee I\right)
$$

in which $I$ indicates the ionic strength, $A$ and $B$ are constants for a given system, $z_{\mathrm{k}}$ is the charge of the ion species $\mathrm{k}$ and $\AA_{\mathrm{k}}$ is an ionic size parameter (Novozamsky et al., 1981). The activity coefficient of the ions in the adsorption phase is taken as unity.

b. Charge-determined adsorption of a species $\mathrm{k}$ with concentration $C(\mathrm{k})$, and charge $z_{\mathrm{k}}$ according to Boltzmann:

$$
C(\mathrm{k})_{\mathrm{a}}=C(\mathrm{k})_{\mathrm{e}} \times \bar{B}^{2 \mathrm{k}}
$$

c. CEC of the montmorillonite. It is assumed that the CEC of the sodium-clay does not change during addition of aluminium.

d. Mass balances including:

- total amounts of ions initially present in and added to the system (including $\mathrm{H}$ and $\mathrm{OH}$ ions).

- distribution of the species over the adsorption phase and equilibrium bulk solution, e.g. in case of sodium:

$$
\mathrm{Na}(\text { tot })=V_{\mathrm{e}} C(\mathrm{Na})_{\mathrm{c}}+V_{\mathrm{a}} C(\mathrm{Na})_{\mathrm{a}}=C(\mathrm{Na})_{\mathrm{c}}\left(V_{\mathrm{c}}+V_{\mathrm{a}} \bar{B}\right)
$$

in which $V_{\mathrm{e}}$ and $V_{\mathrm{a}}$ indicate the volume of the equilibrium bulk solution and adsorption phase, respectively. The latter is estimated according to:

$$
V_{\mathrm{a}}=S \times d_{\mathrm{ex} . \mathrm{an}}
$$

in which $S$ is the specific surface area, taken as $780 \mathrm{~m}^{2} / \mathrm{g}$ for montmorillonite and $d_{\text {ex,an }}$ is the effective distance of exclusion of the anions in the diffuse double layer (de Haan, 1965; Bolt, 1981).

Based on known amount of sodium clay, total amounts of sodium and aluminium added to the system (in case of sodium-aluminium clay systems) and total volume of the solution phase, the model provides the necessary information to calculate the $\bar{B}$ value, the $\mathrm{pH}$ and the activities and/or amounts of the species present in the adsorption phase and in the bulk solution.

The $\mathrm{pH}$ is a good parameter to check the model; it can be measured simply and accurately and its value is very sensitive to a change of conditions in the system.

\section{Experimental}

A homoionic sodium montmorillonite (Wyoming Clay Spur, $<2 \mu \mathrm{m}$ ) in equilibrium with $0.3 \mathrm{mmol} / 1 \mathrm{NaCl}$ was titrated at room temperature with a $0.1 \mathrm{mmol} / 1 \mathrm{AlCl}_{3}$ so- 
lution, using a Radiometer X100 titrator. The $\mathrm{pH}$ was monitored with a Mettler $\mathrm{mV}$ recorder. After an equilibration time of 24 hours the suspension was centrifuged and the concentrations of sodium, chloride and aluminium in the supernatant were measured. Then the residue was shaken for 24 hours with $1 \mathrm{~mol} / \mathrm{l} \mathrm{KCl}$, centrifuged and the concentration of sodium and aluminium in the supernatant were determined. The residue was extracted again, this time with $1 \mathrm{~mol} / \mathrm{K} \mathrm{KCl}$ adjusted with $\mathrm{HCl}$ to $\mathrm{pH} 2.5$. Titrations and subsequent analyses were also carried out for systems with increasing amounts of $\mathrm{AlCl}_{3}$ added, namely ca. $0.25,0.5,0.75,1.0,1.25,1.5$, 2.0, 2.5 and 3 me aluminium per me sodium clay. The titration where 3 me aluminium per me sodium clay was added, was repeated with a solution of $\mathrm{NaCl}-\mathrm{AlCl}_{3}$ at a salt level equivalent to $10^{-2} \mathrm{~mol} / 1 \mathrm{Cl}^{-}$. In this case only the $\mathrm{pH}$ was measured.

Aluminium was determined spectrophotometrically, using eriochrome cyanine $\mathrm{R}$, sodium was measured by flame photometry and chloride by potentiometric titration with $\mathrm{AgNO}_{3}$.

\section{Results and discussion}

Fig. 1 gives the experimental results and model calculations of the interaction of $\mathrm{AlCl}_{3}$ with sodium montmorillonite at a salt level of $3.0 \times 10^{-4} \mathrm{~mol} / 1 \mathrm{Cl}^{-}$. In the first series of aluminium additions, up to 1 me aluminium per me clay, the desorption of sodium ions is almost equal to the aluminium adsorption, the latter expressed as trivalent aluminium ions. Extraction with $1 \mathrm{~mol} / \mathrm{KCl}$ exchanges $90 \%$ or more of the adsorbed aluminium ions for potassium ions. The small remainder is extracted with acidified $1 \mathrm{~mol} / 1 \mathrm{KCl}(\mathrm{pH} 2.5$ ). These results indicate that, under the present experimental conditions, the interaction between aluminium and sodium montmorillonite is dominated by the adsorption of $\mathrm{Al}^{3+}$ ions.

At aluminium additions over 1 me per me clay the adsorption of aluminium (expressed as trivalent ions) exceeds the CEC. This 'superequivalent' aluminium adsorption is not accompanied by $\mathrm{Cl}^{-}$adsorption (experimental data not given here); obviously the adsorbed species shift towards the formation of aluminium hydroxide polymers. Extraction with $1 \mathrm{~mol} / 1 \mathrm{KCl}$ exchanges an amount of aluminium equal to the CEC, when expressed as trivalent ions. The non-exchangeable aluminium can be extracted with acidified $1 \mathrm{~mol} / 1 \mathrm{KCl}(\mathrm{pH} 2.5)$, although more than one extraction would be necessary for complete recovery of the aluminium after high aluminium additions.

These phenomena are in agreement with the selective adsorption precipitation model. A development of a difference between the IAP $_{a}$ and the IAP $_{e}$ as a consequence of the distribution of the added aluminium ions, is counteracted by the charge-determined selectivity which maintains $\operatorname{IAP}_{a}=\operatorname{IAP}_{e}$. This results in a high aluminium concentration in the adsorption phase which is $\mathrm{H}$ ion depleted (i.e. the $C\left(\mathrm{H}^{+}\right) / C\left(\mathrm{Al}^{3+}\right)$ ratio is lower than in a $\mathrm{SN}$ aluminium salt solution with the same aluminium concentration) and in a low aluminium concentration in the equilibrium bulk solution which is $\mathrm{H}$ ion enriched.

At low aluminium additions, the aluminium concentration in the equilibrium bulk solution remains very low. So the amount of protons produced because of ad- 


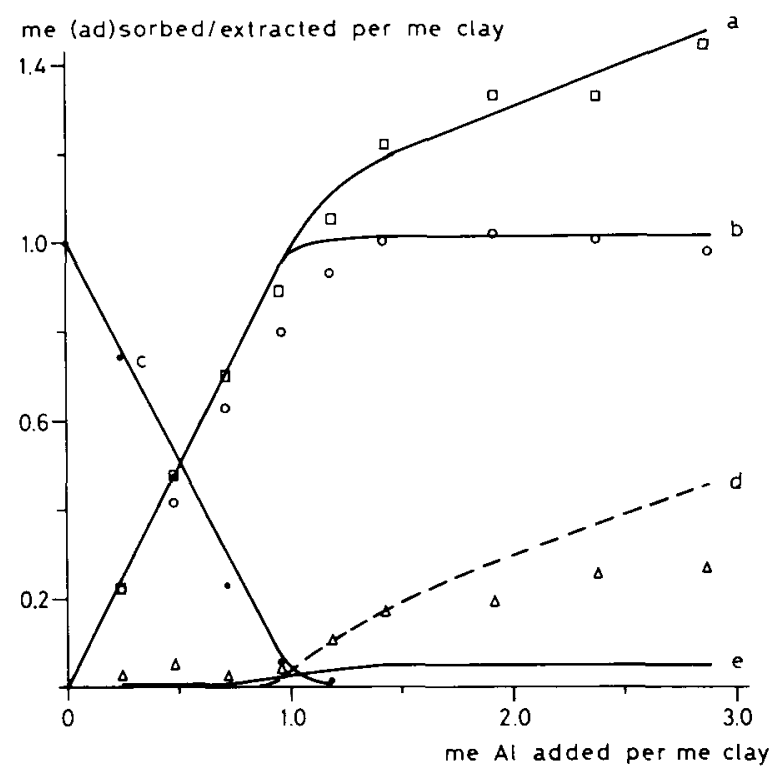

Fig. 1. Titration of sodium montmorillonite suspension with $\mathrm{AlCl}_{3}$ at a total $\mathrm{Cl}^{-}$concentration of 0.3 mmol/l. Lines: computed with the selective adsorption precipitation model. Marked points: experimental results (aluminium expressed as $\mathrm{Al}^{3+}$ ).

a: total aluminium $(\mathrm{ad})$ sorbed (equals $b+d$ ); squares: aluminium added minus aluminium in solution phase before extraction with $\mathrm{KCl}$ solution.

b: total exchangeable aluminium (including e); circles: aluminium exchanged with $1 \mathrm{~mol} / \mathrm{K} \mathrm{KCl}$.

c: sodium adsorbed; dots: sodium exchanged with $1 \mathrm{~mol} / \mathrm{l} \mathrm{KCl}$.

$\mathrm{d}: \mathrm{Al}(\mathrm{OH})_{3}(\mathrm{~s})$; triangles: aluminium extracted with acidified $1 \mathrm{~mol} / \mathrm{K} \mathrm{KCl}(\mathrm{pH} 2.5)$.

e: adsorbed aluminium hydroxides $\left(\mathrm{Al}(\mathrm{OH})^{2+}+\mathrm{Al}_{2}(\mathrm{OH})_{3}^{3+}+\mathrm{Al}_{2}(\mathrm{OH})_{2}^{4+}\right)$.

sorption, necessary to keep $\operatorname{IAP}_{\mathrm{a}}=\mathrm{IAP}_{\mathrm{e}}$, is also small. Upon further addition of $\mathrm{AlCl}_{3}$ the amount of aluminium staying in the equilibrium bulk solution will increase. Consequently the production of protons, necessary to maintain $\operatorname{IAP}_{\mathrm{a}}=$ IAP $_{e}$ also increases. The depletion of $\mathrm{H}$ ions in the adsorption phase with its high aluminium concentration favours high IAP values and may lead to the formation of $\mathrm{Al}(\mathrm{OH})_{3}(\mathrm{~s})$, with $\mathrm{IAP}_{\mathrm{a}}$ being reflected by the solubility product, $K_{\mathrm{sp}}$, of fresh $\mathrm{Al}(\mathrm{OH})_{3}(\mathrm{~s})$. Formation of $\mathrm{Al}(\mathrm{OH})_{3}(\mathrm{~s})$ continues until sufficient $\mathrm{H}$ ions have been produced and distributed over both phases, resulting in $\mathrm{IAP}_{\mathrm{e}}=K_{\mathrm{sp}}=\mathrm{IAP}_{\mathrm{a}}$. The formation of $\mathrm{Al}(\mathrm{OH})_{3}(\mathrm{~s})$ from adsorbed aluminium will be compensated by a secondary adsorption reaction which again is charge-determined, i.e. $\mathrm{Al}^{3+}$ adsorption is preferred. This sequence of events leads to the measured 'superequivalent' sorption of aluminium ions with the exchangeable aluminium equal to the CEC.

Also the speciation of the adsorbed aluminium ions and sodium ions as a function of aluminium added has been calculated with the model; results are also given in Fig. 1. The calculated total amounts of aluminium sorbed (expressed as trivalent ions) are close to the measured amounts. The calculated sodium adsorption is 


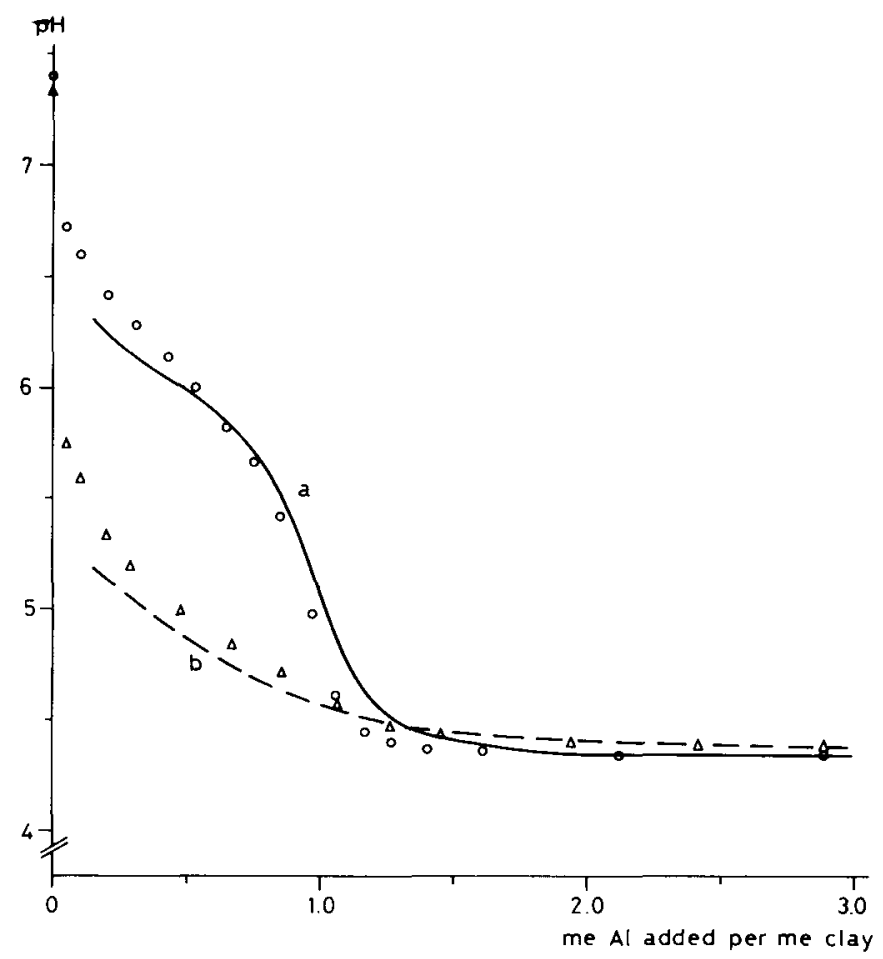

Fig. 2. Titration curves of sodium montmorillonite with $\mathrm{AlCl}_{3}$. a: $\mathrm{Cl}^{-}$concentration $0.3 \mathrm{mmol} / 1 ; \mathrm{b}: \mathrm{Cl}^{-}$ concentration $10 \mathrm{mmol} / \mathrm{l}$. (Lines computed with the model.)

somewhat higher than the measured values at low addition of aluminium. The same holds true for the calculated exchangeable aluminium ions, which are up to $10 \%$ higher than the measured amounts of aluminium exchanged at extraction with 1 $\mathrm{mol} / \mathrm{K} \mathrm{KCl}$. At high aluminium additions the model predicts more precipitation of $\mathrm{Al}(\mathrm{OH})_{3}(\mathrm{~s})$ than the amount of aluminium extracted with $1 \mathrm{~mol} / \mathrm{K} \mathrm{KCl}(\mathrm{pH} 2.5)$. As mentioned before, this acidified $\mathrm{KCl}$ solution probably did not extract all the $\mathrm{Al}(\mathrm{OH})_{3}(\mathrm{~s})$ present.

Fig. 2 gives the measured $\mathrm{pH}$ as a function of $\mathrm{AlCl}_{3}$ added to sodium montmorillonite at a total $\mathrm{Cl}^{-}$concentration of 0.3 and $10 \mathrm{mmol} / \mathrm{l}$, respectively. Application of the model for the same titration, taking the volume of the adsorption phase equal to $1 \mathrm{~cm}^{3}$ per $\mathrm{g}$ clay, is presented by the full drawn lines. The calculated results are close to the measured ones. This strongly supports the applicability of the model. (The present version of the computer program used for the model calculations had some stability problems at low amounts of aluminium added, which explains the lack of data in that area.)

The model also describes phenomena of aluminium-clay interaction as reported in the literature. According to the model, the magnitude of the proton depletion 
and $\mathrm{Al}(\mathrm{OH})_{3}(\mathrm{~s})$ formation in the adsorption phase and the proton enrichment of the equilibrium bulk solution during the addition of aluminium to the clay is a function of the aluminium/clay ratio and the Boltzmann adsorption factor $B$. The latter depends on the electrolyte level and the type of competing cations. Measurable amounts of $\mathrm{Al}(\mathrm{OH})_{3}(\mathrm{~s})$ will be formed when substantial amounts of aluminium remain in the equilibrium bulk solution. In case of sodium-aluminium montmorillonite at a low electrolyte level, the competition of sodium is very little and therefore the aluminium concentration is extremely low at aluminium additions lower than 1 me per me clay. So under these circumstances little or no $\mathrm{Al}(\mathrm{OH})_{3}(\mathrm{~s})$ is formed. At a higher electrolyte concentration or in the presence of a cation adsorbed more strongly than sodium, for example calcium, the formation of non-exchangeable aluminium $\left(\mathrm{Al}(\mathrm{OH})_{3}(\mathrm{~s})\right)$ already occurs at smaller aluminium additions (Bloom et al., 1977). So the amount of irreversibly (ad)sorbed aluminium depends on the aluminium/clay ratio, electrolyte level, type of competing cations and other conditions during the addition of aluminium to the clay. Irreversible (ad)sorption can also be induced by extraction procedures. Replacement of the equilibrium bulk solution enriched in $\mathrm{H}$ ions, by extraction with a neutral salt solution at low electrolyte level and establishing of a new equilibrium, leads to increased formation of $\mathrm{Al}(\mathrm{OH})_{3}(\mathrm{~s})$. So repeated extraction and removal of the equilibrium bulk solution induces formation of non-exchangeable aluminium. The process in fact involves titration of adsorbed $\mathrm{Al}^{3+}$ with neutral salt. This process is more effective the lower the salt level and the lower the charge of the competing cations since these two factors enhance the proton enrichment of the extractant (Bruggenwert, 1972). This also explains the decrease in $\mathrm{H} / \mathrm{Al}$ ratio with increasing ionic strength in the extracts of $M$ - $\mathrm{Al}$ clay as observed by Kaddah \& Coleman (1967).

Upon addition of a neutral salt to an aluminium clay suspension, the Boltzmann factor will decrease which results in a decrease in the difference between the aluminium concentration in the adsorption phase and in the equilibrium bulk solution. In combination with the selective adsorption $\left(\mathrm{IAP}_{\mathrm{a}}=\mathrm{IAP}_{\mathrm{e}}\right.$ ) this effect increases the $\mathrm{pH}$ in the adsorption phase and simultaneously decreases the $\mathrm{pH}$ in the equilibrium bulk solution: the salt effect.

The discussion concerning the influence of the clay on the degree of hydrolysis of aluminium ions deserves some extra attention. The change of the degree of hydrolysis during the titration of a clay with aluminium is shown by the experimental results of Table 1. At the first aluminium additions the $\mathrm{pH}$ in the system is high and, consequently, the mean charge per aluminium atom in the equilibrium bulk solution is low. The mean charge per aluminium atom in the adsorption phase, however, is high. At increasing aluminium additions the $\mathrm{pH}$ decreases and the mean charge per aluminium atom in the equilibrium bulk solution increases, while that in the sorption phase decreases. Thus the model reconciles the theory of preferential adsorption of $\mathrm{Al}^{3+}$ resulting in suppressed hydrolysis (Frink \& Peech, 1963) with the theory of increased hydrolysis (Ragland \& Coleman, 1960; and others) without the need to invoke two types of adsorption sites on the clay mineral (Hodges \& Zelazny, 1983). 
Table 1. Mean charge per aluminium atom in adsorption phase and equilibrium bulk solution, respectively.

\begin{tabular}{llll}
\hline $\begin{array}{l}\text { Al added } \\
\text { (me/me clay) }\end{array}$ & $\mathrm{pH}$ & \multicolumn{2}{l}{ Mean charge per Al atom } \\
\cline { 2 - 2 } & & sorbed & in solution \\
0.24 & 6.4 & 3.0 & 2.0 \\
0.48 & 6.0 & 2.6 & 2.1 \\
0.72 & 5.77 & 2.8 & 2.1 \\
0.96 & 5.11 & - & 2.4 \\
1.19 & 4.57 & 2.7 & 2.7 \\
1.43 & 4.46 & 2.5 & 2.8 \\
2.39 & 4.36 & 2.3 & 2.8 \\
2.87 & 4.37 & 2.0 & 2.8 \\
\hline
\end{tabular}

\section{Conclusions}

The model presented involves the effect of adsorption, charge-determined selectivity and chemical equilibria among aluminium species and satisfactorily describes the aluminium speciation in an aluminium clay system. Phenomena such as the salt effect, partially irreversible (ad)sorption and the shift in the degree of hydrolysis of aluminium ions upon addition of aluminium ions to clay can be described in a coherent way. The model resolves the apparent discrepancy in the literature between supporters of 'increased' and 'suppressed' hydrolysis following the addition of a solution of aluminium salt to a clay system.

\section{Acknowledgements}

The authors are grateful to Professor G. H. Bolt for stimulating discussions. They also express their appreciation to $\mathrm{Mr} \mathrm{E}$. M. Wittich who carried out most of the experiments.

\section{References}

Bloom, P. R., M. B. McBride \& B. Chadbourne, 1977. Adsorption of aluminum by a smectite: surface hydrolysis during $\mathrm{Ca}^{2+}-\mathrm{Al}^{3+}$ exchange. Soil Science Society of America Journal. 41: 1068-1073.

Bolt, G. H., 1981. Adsorption of anions by soil. In: G. H. Bolt \& M. G. M. Bruggenwert (Eds.), Soil Chemistry. A. Basic elements, 3rd ed., p. 91-95. Elsevier, Amsterdam.

Brosset, C., G. Biedermann \& L. G. Sillén, 1954. Studies on the hydrolysis of metal ions XI. The aluminium ion $\mathrm{Al}^{3+}$. Acta Chemica Scandinavica 8: 1917-1922.

Brown, G. \& A. C. D. Newman, 1973. The reactions of soluble aluminium with montmorillonite. Journal of Soil Science 24: 339-355.

Bruggenwert, M. G. M., 1972. Adsorption of Al ions on the clay mineral montmorillonite. (In Dutch.) Doctoral Thesis, Wageningen Agricultural University, $113 \mathrm{pp}$.

Chernov, V. A., 1947. The nature of soil acidity. Academy of Sciences, USSR.

Coleman, N. T. \& G. W. Thomas, 1967. The basic chemistry of soil acidity. In: R. W. Pearson \& F. Adams (Eds.), Soil acidity and liming, p. 1-41. Agronomy Series No 12. American Society of Agronomy, Madison, WI, USA. 
Coulter, B. S., 1969. The chemistry of hydrogen and aluminium in soils, clay minerals and resins. Soils and Fertilizers 32: 215-223.

Faucherre, J., 1954. Sur la constitution des ions basiques métalliques. Bulletin Societé Chimique Française 21: 253-258.

Frink, C. R., 1960. Reactions of the aluminum ion in aqueous solutions and clay suspensions. Doctoral thesis, University of Cornell, $95 \mathrm{pp}$.

Frink, C. R. \& M. Peech, 1963. Hydrolysis and exchange reactions of the aluminum ion in hectorite and montmorillonite suspensions. Soil Science Society of America Proceedings 27: 527-530.

Haan, F. A. M. de, 1965. The interaction of certain inorganic anions with clays and soils. Doctoral thesis, Agricultural University Wageningen, $167 \mathrm{pp}$.

Haward, M. E. \& N. T. Coleman, 1954. Some properties of H and Al clays and exchange resins. Soil Science 78: 181-188.

Hodges, S. C. \& L. W. Zelazny, 1983. Influences of $\mathrm{OH} / \mathrm{Al}$ ratios and loading rates on aluminum kaolinite interaction. Soil Science Society of America Journal 47: 221-225.

Hsu, P. H. \& C. I. Rich, 1960. Aluminium fixation in a synthetic cation exchanger. Soil Science Society of America Proceedings 24: 21-25.

Kaddah, M. T. \& N. T. Coleman, 1967. Salt displacement and titration of $\mathrm{AlCl}_{3}$-treated trioctohedral vermiculite. Soil Science Society of America Proceedings 31: 328-332.

Kenttämaa, J., 1955. The hydrolysis of aluminium chloride. Suomalainen Tiedeakatemia Toim, Sarja A2, Chemica 67: 1.

Kubota, H., 1956. Properties and volumetric determination of aluminum ion. Doctoral thesis, University of Wisconsin.

Novozamsky, I., J. Beek \& G. H. Bolt, 1981. Chemical equilibria. In: G. H. Bolt \& M. G. M. Bruggenwert (Eds.), Soil chemistry. A. Basic elements, 3rd ed., p. 13-42. Elsevier, Amsterdam.

Nye, P. D., N. T. Graig, N. T. Coleman \& J. L. Ragland, 1961. Ion exchange equilibria involving aluminum. Soil Science Society of America Proceedings 25: 14-17.

Ragland, J. L. \& N. T. Coleman, 1960. The hydrolysis of aluminum salts in clay and soil systems. Soil Science Society of America Proceedings 24: 457-460.

Schofield, R. R. \& A. W. Taylor, 1954. The hydrolysis of aluminium salt solutions. Journal Chemical Society $4: 4445-4450$.

Sillén, L. G. \& A. C. Martell, 1964. Stability constants of metal-ion complexes, 2nd ed. Special Publication 25. The Chemical Society, London. 